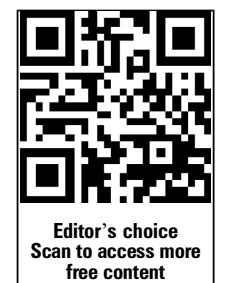

free content

- Additional material is published online only. To view please visit the journal online (http://dx.doi.org/10.1136/ sextrans-2013-051357).

Division of Public Health and Primary Care, Brighton and Sussex Medical School, Brighton, UK

\section{Correspondence to}

Tom Nadarzynski, Division of Public Health and Primary Care, Brighton and Sussex Medical School, Room 321, Mayfield House, Falmer, Brighton BH1 9PH, UK; t.nadarzynski@bsms.ac.uk

Received 10 September 2013 Revised 30 January 2014 Accepted 2 April 2014 Published Online First 30 April 2014

\section{SLinked}

- http://dx.doi.org/10.1136/ sextrans-2014-051637

CrossMark

To cite: Nadarzynski T, Smith H, Richardson D, et al. Sex Transm Infect 2014;90:515-523.

\title{
Human papillomavirus and vaccine-related perceptions among men who have sex with men: a systematic review
}

\author{
Tom Nadarzynski, Helen Smith, Daniel Richardson, Christina J Jones, \\ Carrie D Llewellyn
}

\section{ABSTRACT}

Background Targeted human papillomavirus (HPV) vaccine could prevent HPV-related cancers and genital warts among men who have sex with men (MSM). In order to develop effective vaccination programmes for MSM, it is crucial to understand their knowledge, beliefs about HPV and attitudes towards HPV vaccine.

Methods A systematic search of 10 databases examined articles investigating HPV knowledge and HPV-related perceptions among MSM. Each paper was assessed to identify potential research directions in the context of targeted HPV vaccination for MSM.

Results We identified 16 studies that included 5185 MSM and conducted mainly in North America. Generally, participants were over 26 years old, had poor-tomoderate knowledge about HPV and were not concerned about HPV-related diseases. Over a half of MSM were willing to accept HPV vaccine, if offered. However, there was large variability in HPV vaccine acceptability, partially due to inconsistencies in methods of ascertainment but also different levels of HPV vaccine awareness.

Conclusions Despite several misconceptions and poor knowledge of HPV infection, MSM might be receptive to HPV vaccination. However, further research is needed to identify which factors contribute to potential vaccine uptake in hypothetical MSM-targeted HPV vaccination. Future studies need to target those MSM with little sexual experience, who would benefit most from HPV vaccination.

\section{INTRODUCTION}

Men who have sex with men (MSM) are at risk of sexually transmitted human papillomavirus (HPV) infection, associated with genital warts, anogenital and oropharyngeal cancers. ${ }^{1-3}$ Due to sexual practices such as receptive anal intercourse, MSM are at greater risk of anal cancer as a consequence of HPV infection than heterosexual men. ${ }^{4}$ The incidence of anal cancer among MSM has risen in the last few decades, and HIV-positive men are at the highest risk ( 78 per 100000 men), even with antiretroviral therapy. ${ }^{5}{ }^{6}$ While effective screening programmes are being developed to reduce anal cancer morbidity, vaccination of MSM against HPV is a valuable preventive measure.

HPV vaccination reduces the risk of genital warts, and consequently, a fall in HPV-related cancers is expected. ${ }^{7}$ Australian data show that female HPV vaccination has resulted in a dramatic decline in genital warts among both vaccinated women and unvaccinated heterosexual men of a similar age, demonstrating that high female vaccination coverage indirectly protects a proportion of heterosexual men through 'herd immunity'. ${ }^{8}$ However, such reduced infection rates have not been observed in MSM, suggesting that vaccinating women will not protect MSM against anal cancer. To reduce the incidence of cervical cancer more effectively, policymakers in the USA, Canada and Australia have recently changed eligibility criteria to include males in HPV immunisation. As such, successful male vaccination in these countries will also reduce HPV-related diseases among MSM. ${ }^{9}$ If affordable, high coverage of gender-neutral HPV vaccination will provide the best preventive opportunities for MSM. However, this strategy is unlikely to be implemented in countries with high coverage levels of female vaccination because of the low anticipated benefit and lack of cost-effective evidence. ${ }^{10}$ This will further increase the health inequalities documented in MSM. ${ }^{11}$

\section{MSM-targeted HPV vaccination}

It is uncertain whether targeting MSM with HPV vaccination could significantly reduce the incidence of HPV-related diseases, although there is early indication that MSM-targeted vaccination in addition to routine female immunisation is likely to be cost-effective for MSM below the age of 26 and potentially therapeutic for seropositive MSM. ${ }^{12-15}$ In order to speculate about the feasibility of such a risk-based strategy, it is crucial to examine HPV vaccine acceptability among MSM, as low vaccine uptake will fail to reduce HPV-related diseases. When preventing cervical cancers, HPV vaccination is most effective before sexual debut, as subsequent sexual experience increases the likelihood of HPV infection. This could be problematic as disclosure of sexual orientation in MSM tends to be after sexual debut. Furthermore, factors such as lack of readiness to discuss same-sex practices with healthcare providers (HCP), difficulty in selfidentifying as gay or bisexual, low awareness of HPV-related diseases and negative attitudes towards HPV vaccination might compromise the effectiveness of targeted vaccination. ${ }^{16}$ It is important to understand which factors contribute to HPV vaccine acceptability among MSM to develop effective preventive programmes. Therefore, we assessed the scientific literature to identify current levels of HPV knowledge, specific beliefs about HPV infection and attitudes towards HPV vaccination among MSM. 


\section{METHODS}

In accordance with PRISMA 2009 guidelines, ${ }^{17} 10$ electronic databases (figure 1) were systematically searched in December 2012 for studies investigating HPV knowledge, beliefs about HPV infection and attitudes towards HPV vaccine among MSM. Database search alerts were set up to identify newly published and relevant articles since the original database search. There were no geographical, time or publication-type restrictions, but only papers published in English were eligible. The references of reviewed articles were also hand-searched. Three international HPV experts and relevant search engines (eg, Google Scholar) were used to identify unpublished papers, reports and conference abstracts. Only articles reporting original quantitative primary data were included. These studies focused on MSM in relation to their sexual practices as well as selfidentified homosexual/gay and bisexual men. Studies aimed at males and measuring sexual orientation but reporting low numbers of MSM participants (ie, less than 30 or $5 \%$ of the sample) were excluded. Data of heterosexual men were excluded. These criteria were established to ensure that the data included in the review were sufficient to draw valuable conclusions in the context of selective vaccination for MSM. No comparisons with heterosexual populations were made.

The lead author (TN) scanned titles and abstracts from each database and fully reviewed articles that met the inclusion criteria. Shortlisted studies were then assessed by two reviewers (TN, CJJ) working independently to extract key data. For studies that reported males in general, specific data about MSM were requested from authors to supplement the published findings.

The STROBE checklist for observational studies ${ }^{18}$ and guidance for assessing risk of bias ${ }^{19}$ were used to examine scientific quality. Two authors (TN, CJJ) assessed each study for its methodological strengths and weaknesses, generalisability of findings, use of theoretical frameworks and reliability of measures to establish scientific quality of reporting. Additionally, we comparatively examined the usefulness of data from each study in the context of hypothetical MSM-targeted HPV vaccination, taking into account the number and age of MSM participants and generalisability of the sample to the wider population of MSM below the age of 26 years. This criterion was in line with current HPV vaccine licence regulations. Based on these evaluations, each article was characterised as having lower, medium or higher comparative quality (table 1).

\section{RESULTS}

\section{Study characteristics}

Five studies involving MSM participants were excluded, ${ }^{20-24}$ and 16 studies (table 1) met the inclusion criteria. ${ }^{25-40}$ All studies were conducted prior to official HPV vaccine recommendation for men in the following countries between 2005 and March 2013: the USA (8), Australia (2), Canada (1), Italy (1), Sweden (1), Puerto Rico (1), Malaysia (1) and Hong Kong (1). Nine studies targeted MSM and seven recruited males regardless of sexual orientation. A total of 5185 men, selfidentified as gay/bisexual, took part in cross-sectional surveys. Most studies did not report separate data for homosexual and bisexual men, so the review reflects a general MSM population. The majority of participants were white, either in education or already holding a higher degree, and living in urban areas. Participants were aged between 16 and 71 years, three studies targeted MSM below the age of $26 .{ }^{33} 36{ }^{39}$ Participants were mainly recruited via convenience sampling within large urban areas: gay community events and meeting points (7), sexual health clinics (4), universities (3) and population-based panels (2). Five studies applied psychological models within their design using constructs from either the Health Belief Model or Theory of Planned Behaviour.

The quality assessment classified two articles as having higher quality, five as medium and nine as lower. We selected two studies as having higher comparative quality because their methodological approach and findings could be generalised to a larger MSM population, likely to be eligible for HPV vaccination. The STROBE checklist (table 2) revealed that descriptions of the measurements' sources/reliability, potential sources of bias in design, anticipated sample size and possible generalisability were frequently omitted from the text.
Figure 1 Review of articles for inclusion in systematic review.

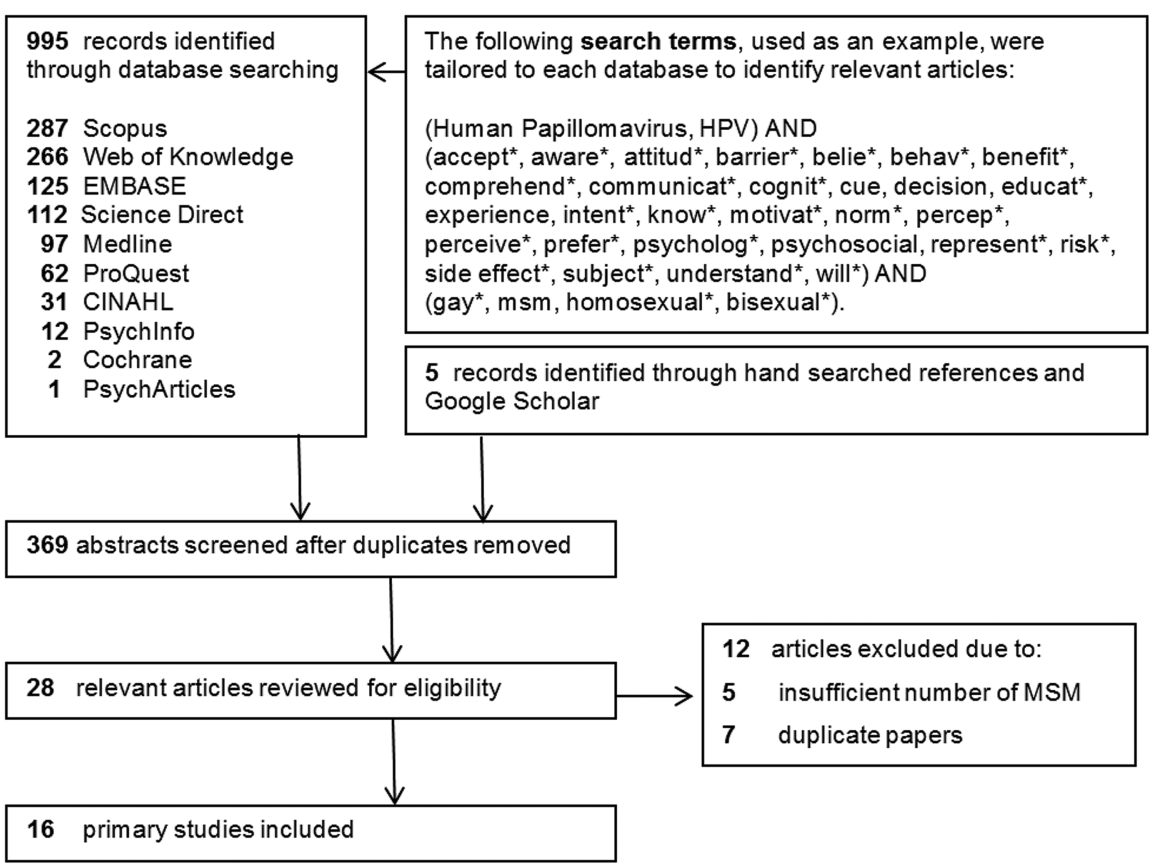


Table 1 The characteristics of 16 studies included in the review, including key variables, HPV vaccine acceptability and the overall quality

\begin{tabular}{|c|c|c|c|c|c|c|c|}
\hline Author (year of publication) & Country & $\begin{array}{l}\text { Number } \\
\text { of MSM }\end{array}$ & Study design & Selected characteristics & Key variables & $\begin{array}{l}\text { HPV vaccine } \\
\text { acceptability }\end{array}$ & $\begin{array}{l}\text { Comparative } \\
\text { quality }\end{array}$ \\
\hline Tider et al $(2005)^{25}$ & USA & 1065 & $\begin{array}{l}\text { Questionnaire at two gay community events in } \\
\text { New York }\end{array}$ & $\begin{array}{l}\text { Mean age }=36(S D=10) \\
65 \% \text { white/European }\end{array}$ & $\begin{array}{l}\text { HPV knowledge } \\
\text { Sexual history }\end{array}$ & NR & Lower \\
\hline Pitts et al $(2007)^{26}$ & Australia & 384 & $\begin{array}{l}\text { Questionnaire at gay community event in } \\
\text { Melbourne }\end{array}$ & $\begin{array}{l}\text { Mean age }=37 \text { (range: } 16-67 \text { ) } \\
58 \% \text { had high education qualification } \\
67 \% \text { in full-time employment }\end{array}$ & $\begin{array}{l}\text { HPV knowledge } \\
\text { HPV information source } \\
\text { HPV risk factors beliefs } \\
\text { Healthcare access }\end{array}$ & NR & Medium \\
\hline Simatherai et al (2009) ${ }^{27}$ & Australia & 200 & $\begin{array}{l}\text { Questionnaire for gay/bisexual men at sexual } \\
\text { health clinic in Melbourne }\end{array}$ & Median age $=27$ (range 19-71) & $\begin{array}{l}\text { Willing to pay } \$ A 450 \text { for HPV vaccine* } \\
\text { HPV awareness } \\
\text { Sexual history } \\
\text { Sexual orientation disclosure }\end{array}$ & $47 \%$ & Lower \\
\hline Reiter et al $(2009)^{28}$ & USA & $312 \dagger$ & $\begin{array}{l}\text { Internet-based questionnaire for males via } \\
\text { pre-existing panel of US households }\end{array}$ & $\begin{array}{l}\text { Age range } 18-59(4.5 \% 18-26) \\
81 \% \text { non-Hispanic white } \\
56 \% \text { had high education qualification } \\
94 \% \text { living in urban area }\end{array}$ & $\begin{array}{l}\text { HPV vaccine acceptability* } \\
\text { HPV knowledge } \\
\text { Concern } \\
\text { Perceived susceptibility } \\
\text { Perceived severity } \\
\text { Perceived vaccine effectiveness } \\
\text { Perceived barriers } \\
\text { Anticipated regret } \\
\text { Cue to action } \\
\text { Sexual history }\end{array}$ & $74 \%$ & Medium \\
\hline Sundstrom et al (2010) $\neq^{29}$ & Sweden & $75 t$ & $\begin{array}{l}\text { Multimodal nationwide survey of } 14000 \text { adults } \\
\text { recruited from the Swedish Population Register }\end{array}$ & $\begin{array}{l}\text { Mean age=24 }(S D=3 \text {, range } 18-31) \\
86 \% \text { born in Sweden } \\
75 \% \text { had high education qualification } \\
55 \% \text { living in rural area }\end{array}$ & $\begin{array}{l}\text { Willingness to get vaccinated* } \\
\text { Willingness to get vaccinated at any cost* } \\
\text { Willingness to pay some cost of the } \\
\text { vaccination* } \\
\text { HPV awareness } \\
\text { Perceived risk } \\
\text { Belief about vaccine } \\
\text { Sexual history } \\
\text { Willingness to pay for vaccine } \\
\text { HPV vaccine information request } \\
\text { Reasons to abstain from HPV vaccine } \\
\text { Beliefs about compensating risk }\end{array}$ & $\begin{array}{l}79 \% \\
7 \% \\
31 \%\end{array}$ & Lower \\
\hline Hernandez et al (2010) $\ddagger^{30}$ & USA & $88+$ & $\begin{array}{l}\text { Questionnaire for males at university campus } \\
\text { and general public in Hawaii }\end{array}$ & $23 \%$ were under 26 years old & HPV vaccine acceptability* & $75 \%$ & Lower \\
\hline $\begin{array}{l}\text { Thomas and Goldstone } \\
(2011)^{31}\end{array}$ & USA & 191 & $\begin{array}{l}\text { Telephone and face-to-face survey at practice for } \\
\text { HPV treatment offering 'off-label' HPV vaccine } \\
\text { for gay/bisexual men }\end{array}$ & $\begin{array}{l}\text { Mean age }=37 \text { (range } 22-56 \text { ) } \\
80 \% \text { white } \\
86 \% \text { previously diagnosed with HPV } \\
50 \% \text { diagnosed with non-HPV STI }\end{array}$ & $\begin{array}{l}\text { Paid for HPV vaccine when offered (uptake)* } \\
\text { HPV knowledge } \\
\text { HPV vaccine information source } \\
\text { Perceived barriers } \\
\text { Perceived benefits } \\
\text { Cue to action } \\
\text { Risk compensation }\end{array}$ & $65 \%$ & Lower \\
\hline Blackwell and Eden (2011) $)^{32}$ & USA & 89 & $\begin{array}{l}\text { Questionnaire at various gay pride and gay } \\
\text { community events }\end{array}$ & $\begin{array}{l}\text { Mean age=32 }(S D=13) \\
75 \% \text { white } \\
31 \% \text { married/living with partner } \\
67 \% \text { had high education qualification }\end{array}$ & $\begin{array}{l}\text { HPV knowledge } \\
\text { HPV information source }\end{array}$ & NR & Medium \\
\hline Wheldon et al $(2011)^{33}$ & USA & 179 & $\begin{array}{l}\text { Internet-based questionnaire for gay/bisexual } \\
\text { men through snowball sampling method via } \\
\text { student organisations at } 23 \text { colleges and } \\
\text { universities in southeast US }\end{array}$ & $\begin{array}{l}\text { Mean age }=21.6(\mathrm{SD}=3) \\
68 \% \text { white } \\
78 \% \text { were in education } \\
39 \% \text { knows someone who received HPV } \\
\text { vaccine } \\
10 \% \text { had no sexual experience }\end{array}$ & $\begin{array}{l}\text { Likely to get vaccinated* } \\
\text { HPV vaccine intentions* } \\
\text { HPV knowledge } \\
\text { Perceived susceptibility } \\
\text { Perceived severity } \\
\text { Perceived benefits }\end{array}$ & $\begin{array}{l}36 \% \text { Mean }=4.5 \\
(\mathrm{SD}=1.3, \text { range } 1-7)\end{array}$ & High \\
\hline
\end{tabular}


Table 1 Continued

\begin{tabular}{|c|c|c|c|c|c|c|c|}
\hline Author (year of publication) & Country & $\begin{array}{l}\text { Number } \\
\text { of MSM }\end{array}$ & Study design & Selected characteristics & Key variables & $\begin{array}{l}\text { HPV vaccine } \\
\text { acceptability }\end{array}$ & $\begin{array}{l}\text { Comparative } \\
\text { quality }\end{array}$ \\
\hline & & & & & $\begin{array}{l}\text { Perceived barriers } \\
\text { Self-efficacy } \\
\text { Attitudes towards HPV vaccine } \\
\text { Subjective norms } \\
\text { Perceived behavioural control }\end{array}$ & & \\
\hline Pelullo et al $(2012)^{34}$ & Italy & $630+$ & $\begin{array}{l}\text { Face-to-face interview at gay community venues } \\
\text { in Naples }\end{array}$ & $\begin{array}{l}\text { Mean age }=26 \text { (SD=7, range: } 16-62) \\
90 \% \text { married } \\
89 \% \text { employed } \\
14 \% \text { had high education qualification }\end{array}$ & $\begin{array}{l}\text { HPV vaccine acceptability* } \\
\text { HPV knowledge }\end{array}$ & NR & Medium \\
\hline Colón-López et al (2012) $\ddagger^{35}$ & $\begin{array}{l}\text { Puerto } \\
\text { Rico }\end{array}$ & $58+$ & $\begin{array}{l}\text { Questionnaire for males and females at sexual } \\
\text { health clinic in San Juan }\end{array}$ & $\begin{array}{l}\text { Mean age }=38(\mathrm{SD}=13) \\
68 \% \text { HIV positive }\end{array}$ & $\begin{array}{l}\text { HPV vaccine willingness* } \\
\text { HPV awareness } \\
\text { HPV vaccine awareness } \\
\text { Perceived susceptibility }\end{array}$ & $21 \%$ & Lower \\
\hline Al-Naggar $(2012) \ddagger^{36}$ & Malaysia & $46+$ & $\begin{array}{l}\text { Questionnaire for males on university campus in } \\
\text { Shah Alam }\end{array}$ & $\begin{array}{l}\text { Mean age }=21(S D=2) \\
100 \% \text { had not heard of HPV vaccine }\end{array}$ & $\begin{array}{l}\text { Likelihood of getting HPV vaccine* } \\
\text { HPV vaccine awareness } \\
\text { Sexual history }\end{array}$ & $0 \%$ & Lower \\
\hline Rank et al (2012) $)^{37}$ & Canada & 1169 & $\begin{array}{l}\text { Questionnaire at various gay community events } \\
\text { in Vancouver }\end{array}$ & $\begin{array}{l}\text { Median age }=33 \\
77 \% \text { white } \\
79 \% \text { had high education qualification } \\
18 \% \text { HIV positive } \\
56 \% \text { have more than } 5 \text { sexual partners } \\
26 \% \text { use recreational drugs } \\
18 \% \text { diagnosed with genital warts }\end{array}$ & $\begin{array}{l}\text { HPV vaccine acceptability* } \\
\text { HPV knowledge } \\
\text { Sexual orientation disclosure }\end{array}$ & $67 \%$ & Higher \\
\hline Sanchez et al (2012) & USA & 116 & $\begin{array}{l}\text { Questionnaire at sexual health clinic } \\
\text { in New York City }\end{array}$ & $\begin{array}{l}\text { Median age }=25 \pm 7.8 \text { (range } 17-62 \text { ) } \\
46 \% \text { non-Hispanic white } \\
10 \% \text { diagnosed with genital warts }\end{array}$ & $\begin{array}{l}\text { HPV vaccine acceptability* } \\
\text { HPV knowledge } \\
\text { Perceived risk }\end{array}$ & $86 \%$ & Lower \\
\hline Gutierrez et al (2013) & USA & $41+$ & $\begin{array}{l}\text { Questionnaire of a community-based } \\
\text { convenience sample in Philadelphia }\end{array}$ & $\begin{array}{l}\text { Median age }=18 \text { (range } 13-21) \\
77 \% \text { African-American }\end{array}$ & $\begin{array}{l}\text { HPV vaccine intentions* } \\
\text { HPV knowledge } \\
\text { Attitudes } \\
\text { Subjective norms } \\
\text { Perceived behavioural control }\end{array}$ & $\begin{array}{l}\text { Mean }=2.6 \\
(S D=1.2 \text {, range } 1-5)\end{array}$ & Lower \\
\hline Lau et al $(2013)^{40}$ & Hong Kong & 542 & $\begin{array}{l}\text { Face-to-face questionnaire at various gay venues } \\
\text { in Hong Kong }\end{array}$ & $\begin{array}{l}25 \% \text { were } 18-25 \text { years old } \\
75 \% \text { were } 26-60 \text { years old }\end{array}$ & $\begin{array}{l}\text { Intention to uptake HPV vaccine* } \\
\text { Intention to pay for the vaccine* } \\
\text { Intention to uptake free HPV vaccine* } \\
\text { HPV knowledge } \\
\text { Perceived susceptibility } \\
\text { Perceived severity } \\
\text { Perceived benefits } \\
\text { Perceived barriers } \\
\text { Perceived self-efficacy } \\
\text { Cues to action } \\
\text { Sexual history }\end{array}$ & $\begin{array}{l}20 \% \\
29 \% \\
79 \%\end{array}$ & Medium \\
\hline
\end{tabular}

* Reference variable for HPV vaccine acceptability/intention.

†Selected number of MSM subjects taken from a larger study sample.

HPV, human papillomavirus; MSM, men who have sex with men; NR, not reported; STI, sexually transmitted infection. 
Table 2 The result of the STROBE checklist assessment for reporting in observational studies

\begin{tabular}{|c|c|c|c|c|c|c|c|c|c|c|c|c|c|c|c|c|c|c|c|c|c|c|}
\hline \multirow{2}{*}{$\begin{array}{l}\text { Author } \\
\text { (year of } \\
\text { publication) }\end{array}$} & \multirow{2}{*}{$\begin{array}{l}\text { Title } \\
\text { and } \\
\text { abstract }\end{array}$} & \multicolumn{2}{|l|}{ Intro } & \multicolumn{9}{|c|}{ Methods } & \multicolumn{5}{|l|}{ Results } & \multicolumn{4}{|c|}{ Discussion } & \multirow[b]{2}{*}{ Funding } \\
\hline & & $\begin{array}{l}\text { Background/ } \\
\text { rationale }\end{array}$ & Objectives & $\begin{array}{l}\text { Study } \\
\text { design }\end{array}$ & Setting & Participants & Variables & $\begin{array}{l}\text { Data sources/ } \\
\text { measurement }\end{array}$ & Bias & $\begin{array}{l}\text { Study } \\
\text { size }\end{array}$ & $\begin{array}{l}\text { Quantitative } \\
\text { variables }\end{array}$ & $\begin{array}{l}\text { Statistical } \\
\text { methods }\end{array}$ & Participants & $\begin{array}{l}\text { Descriptive } \\
\text { data }\end{array}$ & $\begin{array}{l}\text { Outcome } \\
\text { data }\end{array}$ & $\begin{array}{l}\text { Main } \\
\text { results }\end{array}$ & $\begin{array}{l}\text { Other } \\
\text { analysis }\end{array}$ & $\begin{array}{l}\text { Key } \\
\text { results }\end{array}$ & Limitations & Interpretation & Generalisability & \\
\hline $\begin{array}{l}\text { Tider et al } \\
(2005)^{25}\end{array}$ & 1 & 1 & 1 & 0 & 0 & 0 & 0 & 0 & 0 & 0 & 0 & 0 & 0 & 0 & 0 & 1 & 0 & 0 & 0 & 0 & 0 & 0 \\
\hline Pitts et al $(2007)^{26}$ & 1 & 1 & 1 & 1 & 1 & 0 & 1 & 0 & 0 & 0 & 0 & 1 & 1 & 1 & 1 & 1 & 0 & 1 & 0 & 0 & 0 & 0 \\
\hline $\begin{array}{l}\text { Simatherai et al } \\
(2009)^{27}\end{array}$ & 1 & 0 & 0 & 0 & 0 & 0 & 1 & 0 & 0 & 1 & 1 & 0 & 0 & 1 & 0 & 1 & 0 & 1 & 0 & 0 & 0 & 0 \\
\hline $\begin{array}{l}\text { Reiter et al } \\
(2009)^{28}\end{array}$ & 1 & 1 & 1 & 1 & 1 & 1 & 1 & 0 & 0 & 1 & 1 & 1 & 1 & 1 & 1 & 1 & 1 & 1 & 1 & 1 & 1 & 1 \\
\hline $\begin{array}{l}\text { Sundstrom et al } \\
(2010)^{29}\end{array}$ & 1 & 1 & 1 & 1 & 1 & 1 & 1 & 1 & 0 & 1 & 0 & 1 & 1 & 1 & 1 & 1 & 1 & 1 & 1 & 1 & 1 & 1 \\
\hline $\begin{array}{l}\text { Hernandez et al } \\
(2010)^{30}\end{array}$ & 1 & 1 & 0 & 1 & 1 & 1 & 1 & 0 & 0 & 1 & 1 & 1 & 1 & 1 & 1 & 1 & 1 & 1 & 1 & 1 & 0 & 1 \\
\hline $\begin{array}{l}\text { Thomas and } \\
\text { Goldstone } \\
(2011)^{11}\end{array}$ & 1 & 1 & 1 & 1 & 1 & 1 & 1 & 0 & 0 & 1 & 1 & 1 & 1 & 1 & 1 & 1 & 1 & 1 & 1 & 1 & 0 & 1 \\
\hline $\begin{array}{l}\text { Blackwell and } \\
\text { Eden } \\
(2011)^{32}\end{array}$ & 1 & 1 & 1 & 1 & 1 & 1 & 1 & 1 & 1 & 1 & 1 & 1 & 1 & 1 & 1 & 1 & 0 & 1 & 1 & 1 & 0 & 1 \\
\hline $\begin{array}{l}\text { Wheldon et al } \\
(2011)^{33}\end{array}$ & 1 & 1 & 1 & 1 & 1 & 1 & 1 & 1 & 1 & 1 & 1 & 1 & 1 & 1 & 1 & 1 & 1 & 1 & 1 & 1 & 0 & 1 \\
\hline $\begin{array}{l}\text { Pelullo et al } \\
(2012)^{34}\end{array}$ & 1 & 1 & 1 & 1 & 1 & 1 & 1 & 1 & 1 & 1 & 1 & 1 & 1 & 1 & 1 & 1 & 1 & 1 & 1 & 1 & 1 & 1 \\
\hline $\begin{array}{l}\text { Colón-López et al } \\
(2012)^{35}\end{array}$ & 1 & 1 & 1 & 1 & 1 & 1 & 1 & 1 & 0 & 0 & 1 & 1 & 1 & 1 & 1 & 1 & 0 & 1 & 0 & 0 & 0 & 1 \\
\hline $\begin{array}{l}\text { Al-Naggar } \\
(2012)^{36}\end{array}$ & 1 & 1 & 1 & 1 & 1 & 1 & 1 & 0 & 0 & 0 & 0 & 1 & 1 & 1 & 1 & 1 & 0 & 1 & 1 & 1 & 0 & 0 \\
\hline $\begin{array}{l}\text { Rank et al } \\
(2012)^{37}\end{array}$ & 1 & 1 & 0 & 1 & 1 & 1 & 1 & 0 & 0 & 1 & 1 & 1 & 1 & 1 & 1 & 1 & 0 & 1 & 1 & 1 & 0 & 1 \\
\hline $\begin{array}{l}\text { Sanchez et al } \\
(2012)^{38}\end{array}$ & 1 & 0 & 0 & 0 & 0 & 0 & 0 & 0 & 0 & 0 & 0 & 0 & 1 & 0 & 1 & 1 & 0 & 1 & 0 & 0 & 0 & 0 \\
\hline $\begin{array}{l}\text { Gutierrez et al } \\
(2013)^{39}\end{array}$ & 1 & 1 & 1 & 1 & 0 & 1 & 1 & 1 & 0 & 0 & 1 & 1 & 1 & 1 & 1 & 1 & 0 & 1 & 1 & 1 & 1 & 1 \\
\hline Lau et al $(2013)^{40}$ & 1 & 1 & 1 & 1 & 1 & 1 & 1 & 0 & 0 & 0 & 0 & 1 & 1 & 1 & 1 & 1 & 1 & 1 & 1 & 1 & 1 & 0 \\
\hline Total & 16 & 14 & 12 & 13 & 12 & 12 & 14 & 6 & 3 & 9 & 10 & 13 & 14 & 14 & 14 & 16 & 7 & 15 & 11 & 11 & 5 & 10 \\
\hline
\end{tabular}




\section{Knowledge about HPV}

The majority of MSM sampled had a poor understanding of HPV and its causal role in cancer. On average, 63\% (range 2093\%, 11 studies) had heard of HPV but fewer (39\%; range 0$86 \%$, five studies) were aware of HPV vaccine. Most MSM were more aware of 'a warts virus' rather than HPV per se. One study demonstrated that $63 \%$ of HPV-infected MSM reported having genital warts, but not HPV. ${ }^{25}$ In a Swedish study, 20\% reported hearing about $\mathrm{HPV}$ and $93 \%$ about condyloma. ${ }^{29}$ Eight studies 26 28 $31-33 \quad 38-40$ used scales to assess HPV knowledge, showing that $36-75 \%$ of MSM associated HPV with sexual activity. While half knew HPV caused genital warts, fewer associated HPV with anal (32-53\%), oral (25-47\%) and penile (28-31\%) cancers. ${ }^{28} 3334$ Between 22\% and 55\% recognised smoking, receptive anal intercourse, multiple sexual partners and unprotected sexual intercourse as the main risk factors for anal cancer. ${ }^{26} 28{ }^{34}$ Half of MSM knew HPV affects both sexes, and that infection may be asymptomatic. ${ }^{28}$ The most cited sources of HPV information were primary care doctors and nurses, other healthcare professionals (HCP), magazines, television adverts, family members and friends. ${ }^{28} 31$

\section{Perceptions of HPV}

The majority of participants did not perceive themselves at risk of HPV or related diseases. There were greater perceptions of vulnerability to genital warts than anal cancer. Half of MSM in the Hong Kong sample had misconceptions about HPV, such as it being of low infectivity or controlled by antibiotics. ${ }^{40}$ Most MSM in the US population-based study reported low levels of concern about developing HPV-related disease. ${ }^{28}$ While $60 \%$ of New York sexual health clinic attendees considered themselves susceptible to HPV, 30\% perceived a risk of anal cancer. ${ }^{38}$ In contrast, three studies indicated that the majority of MSM thought HPV-related diseases such as anal cancer were severe and had a potentially damaging impact on health. ${ }^{28} 3340$

\section{Attitudes towards HPV vaccine}

Most MSM showed positive attitudes towards HPV vaccine. Two studies reported that MSM believed HPV vaccination would be good, safe, smart, easy, important and harmless. ${ }^{33} 39$ In general, MSM considered the HPV vaccine effective in preventing HPV-related diseases, with one study indicating lower perceived effectiveness in preventing genital warts than cancers. ${ }^{40}$ One study showed that young MSM believed they would be generally encouraged by their family and friends to be vaccinated. ${ }^{39}$ Five studies showed that MSM were concerned about high vaccine costs and possible side effects. ${ }^{28-30} 3340$ Factors such as fear of needles or difficulties accessing the clinic were perceived as potential barriers to receive the vaccine. ${ }^{30}$ MSM expressed concerns about HPV vaccine safety, availability, lack of approval from healthcare authorities and number of doses needed to be effective. $^{28-30}{ }^{40}$ In two studies, 78\% of MSM had disclosed same-sex practices to their HCP and 93\% would be willing to disclose their sexual orientation in order to be vaccinated. ${ }^{27} 37$ MSM would also largely regret refusing HPV vaccination if diagnosed with HPV-related cancer later in life. ${ }^{28}$

\section{HPV vaccine acceptability}

Over half of MSM would accept HPV vaccination (mean $=56 \%$, median $=65 \%$, range $0-86 \%, 12$ studies). There were no clear trends in HPV vaccine acceptability across various sampling venues, time of data collection and geographical location. To determine vaccine acceptability, four studies used willingness to receive the vaccine, ${ }^{28-30} 37$ three willingness to pay for the vaccine, ${ }^{27} 2940$ one likelihood of getting the HPV vaccine, ${ }^{36}$ three intentions to be vaccinated ${ }^{33^{3}} 39^{40}$ and one estimated actual vaccine uptake status when it was offered 'off-label'. 31 The results were highly heterogeneous, and there were large differences between measures. For example, surveys that measured hypothetical intentions to receive the vaccine as an approximation of vaccine acceptability reported lower rates than those asking about willingness to receive HPV vaccine.

Awareness about HPV vaccine was related to vaccine acceptability. The studies conducted in the USA reported generally higher rates of HPV awareness and also greater willingness to be vaccinated. $^{28} \quad 30-313338$ For example, $85 \%$ of MSM from a New York sexual health clinic had heard of HPV and $86 \%$ reported willingness to receive the vaccine. ${ }^{38}$ In contrast, none of the Malaysian MSM participants had previously heard of HPV vaccine and none considered themselves likely to receive it. ${ }^{36}$

Studies asking about willingness to pay reported lower acceptability than studies not addressing cost. Proposed greater personal vaccination cost was also associated with lower vaccine acceptability. While $41 \%$ of MSM in the Swedish sample would accept the vaccine if free of charge, only 7\% would accept it at any cost. ${ }^{29}$ Similarly, participants from Hong Kong showed higher rates of intention to be vaccinated when the HPV vaccine was free compared with \$1000-2000 per shot (79\% vs $29 \%)$. $^{40}$

Three studies reported no significant associations between the age of participants and vaccine acceptability, demonstrating that there was no difference in willingness to be vaccinated between younger and older MSM. ${ }^{28} 3337$ One study also showed that there were no differences in HPV knowledge associated with age. ${ }^{26}$

Table 3 summarises statistically significant correlates of HPV vaccine acceptability among MSM across five studies. ${ }^{28} 31333740$ The most frequently cited correlates of MSM HPV vaccine acceptability were HPV knowledge, perceived severity of HPV-related diseases, perceived risk of HPV-related diseases, perceived benefits of HPV vaccine and doctor's recommendation.

\section{DISCUSSION}

This review demonstrates that MSM showed insufficient knowledge of HPV-related cancers and the availability of HPV vaccine as a method of prevention. Most MSM failed to recognise HPV risk; however, anogenital cancers were generally perceived as severe. Despite little knowledge, more than half of MSM were willing to accept HPV vaccination. The observed differences in acceptability could be explained by variations in HPV awareness, specific barriers such as perceived vaccine cost, uncertainty about personal eligibility, side effects and perceptions of vaccine effectiveness. These findings are useful in the context of targeted vaccination, as little knowledge about HPV, low perceived susceptibility to HPV infection, negative attitudes towards the vaccine and lack of readiness to discuss same-sex practices with HCPs are likely to compromise the effectiveness of this preventive method. Previous studies have shown that individuals unaware of their risk and those with negative attitudes are less likely to adopt self-protective behaviours. ${ }^{41} 42$

Nevertheless, for individuals unaware of HPV, attitudes such as the willingness to accept vaccination are likely to be constructed instantly rather than revealed if faced with vaccination offer. These attitudes are usually weak, unstable and most likely dependent on the environment under which the decision is made. ${ }^{43}$ It is possible that unaware MSM would construct stronger HPV vaccination preferences when facing doctor's recommendation in a clinical setting rather than answering a vaccine-related questionnaire. Therefore, future studies need to 
Table 3 Summary of statistically significant correlates of HPV vaccine acceptability among MSM presented in five studies

\begin{tabular}{|c|c|}
\hline Acceptability correlates & Reference \\
\hline \multicolumn{2}{|l|}{ Positive correlates } \\
\hline \multicolumn{2}{|l|}{ Demographic variables } \\
\hline Educational attainment-having a degree & 33 \\
\hline$>\$ 20000$ income & 37 \\
\hline \multicolumn{2}{|l|}{ Behavioural correlates } \\
\hline Number of lifetime sexual partners & 28 \\
\hline Ever diagnosed with genital warts & 37 \\
\hline Vaccinated for hepatitis A or B & 37 \\
\hline Identified as MSM to HCP & 37 \\
\hline Exposed to HIV-related services in the last year (peer education) & 40 \\
\hline Watching media reports promoting HPV vaccine & 40 \\
\hline Knowledge about HPV and HPV vaccine & 31,40 \\
\hline Heard of HPV & 37 \\
\hline \multicolumn{2}{|l|}{ Psychosocial correlates } \\
\hline Concern about getting HPV-related disease & 28 \\
\hline Perceived severity of HPV-related disease & $28,33,40$ \\
\hline Perceived likelihood of getting HPV-related disease & 28,33 \\
\hline Anticipated regret & 28 \\
\hline Perceived effectiveness of HPV vaccine & 28 \\
\hline Perceived benefits of HPV vaccination & 33,40 \\
\hline Attitudes towards HPV vaccine & 33 \\
\hline Belief that doctor would recommend HPV vaccine & 28,40 \\
\hline Belief that peers would recommend HPV vaccine & 40 \\
\hline \multicolumn{2}{|l|}{ Negative correlates } \\
\hline \multicolumn{2}{|l|}{ Behavioural correlates } \\
\hline Not using recreational drugs before or during sex & 37 \\
\hline Age of first oral sex with a man & 31 \\
\hline Unprotected anal intercourse in the last 6 months & 40 \\
\hline \multicolumn{2}{|l|}{ Psychosocial correlates } \\
\hline Perceived barriers to HPV vaccination (cost, safety) & 33 \\
\hline Belief that HPV vaccine is a sign of promiscuity & 40 \\
\hline Not self-identified as gay & 37 \\
\hline
\end{tabular}

assess HPV vaccine acceptability in the specific context of MSM-targeted vaccination incorporating information about the potential compromised effectiveness (due to the risk of HPV infection), settings, price, delivery methods and so on. We recommend that future acceptability measures portray scenarios, under which the hypothetical decision is going to be made, in order to increase individual understanding of the vaccination context, assess vaccine desirability and to identify the consistency of these preferences.

HPV awareness might be related to vaccine acceptability, and therefore, it is crucial to examine whether educating MSM about HPV would predict higher vaccine acceptability. Additional health promotion could also encourage younger MSM to disclose sexual orientation to enable discussion of HPV vaccine availability. Knowledge about hepatitis B vaccine and openness about sexual orientation to HCPs predicts hepatitis B vaccination. ${ }^{44}$ UK data demonstrate a $90 \%$ uptake of hepatitis B vaccine among MSM at sexual health clinics, suggesting MSM are willing to adopt protective behaviours against sexually transmitted infections (STIs). ${ }^{45}$ Australian data indicate that high coverage of MSM-targeted hepatitis B vaccination has contributed to increased levels of hepatitis B immunity in MSM. ${ }^{46}$ Although this suggests that MSM-targeted vaccination is acceptable and achievable, uncertainty exists as to what degree HPV and hepatitis B vaccination strategies can be compared across various healthcare systems and countries. Consideration should be also given to the specific additional resources needed for this strategy to succeed such as information campaigns encouraging vaccination when evaluating its practicability.

The feasibility of targeted vaccination in various settings (eg, primary care, pharmacies, specialised sexual health services, alternative settings ${ }^{47}$ ) needs to be explored to identify strategies to enable a large number of MSM to accept HPV vaccination. Willingness to accept HPV vaccine at an early stage of sexual activity is likely to play an important role in establishing effectiveness of this risk-based strategy. Correspondingly, future studies need to examine HCP's attitudes towards offering HPV vaccination to their MSM patients and identify potential training requirements, as doctor's recommendation is a significant factor likely to influence the efficacy of this strategy.

\section{Methodological issues}

There is wide variation in individual study designs, methodological approaches and characteristics of MSM resulting in limited comparability of findings. There is no standardised measurement of vaccine acceptability, and researchers report willingness, intentions or likelihood when referring to the hypothetical openness and readiness to receive HPV vaccination. These constructs are likely to represent different psychological properties and could introduce bias when estimating vaccine desirability or uptake rates. ${ }^{48}$ For example, participants unaware of HPV might be unable to construct intentions to be vaccinated, indicating restrictions of this measurement when assessing hypothetical behaviours. As such, there is a need to develop a sensitive and standardised measurement of vaccine acceptability that could be incorporated in modelling of vaccination behaviour.

The earlier studies present lower quality and the applicability of findings when estimating the feasibility of MSM-targeted HPV vaccination. While nine studies recruited MSM, seven were aimed at males in general, restricting generalisability of findings. Inability to relate the content of the questionnaire to individual circumstances might influence the validity of results. Two studies attempted to recruit MSM via populationrepresentative sampling, whereas most studies were conducted in predominantly urban places likely to be visited by MSM (eg, gay pride, sexual health clinic). These sampling methods are likely to attract MSM with substantial sexual experience. Only three studies focused on perceptions and preferences of MSM below the age of 26 who would most benefit from vaccination against HPV. Future studies need to focus on younger MSM, as this group is most relevant for HPV vaccination. Studies used various measurements of HPV knowledge, and it was challenging to distinguish whether participants were primed with any information about HPV. Any form of priming could influence vaccine acceptability. Only five studies incorporated theoretical frameworks when examining correlates of HPV vaccine acceptability. It is important to understand how MSM perceive their own risk and whether HPV information would result in positive attitudes towards HPV vaccination. Finally, seven studies assessed sexual history and additional behavioural data enhance the understanding of whether sexual experience is associated with vaccine acceptability.

\section{CONCLUSION}

Despite poor knowledge about HPV, most MSM are receptive to HPV vaccination. Future intervention studies need to 
examine whether awareness campaigns with corresponding doctor's recommendation result in higher HPV vaccine acceptability. In order to design the most optimal MSM-targeted HPV vaccination programmes, it is essential to understand which demographic, behavioural and psychosocial factors correlate with vaccine acceptability among MSM. We recommend that future studies focus on MSM with little sexual experience, apply measures of acceptability that incorporate specific vaccination scenario, use theoretical frameworks and define predictors of HPV vaccine acceptability and uptake. It is crucial to understand factors that would enable sexual orientation disclosure of young MSM and whether offering a vaccination combination for both HPV and hepatitis B could potentially attract a larger number of MSM willing to be vaccinated. As such, in the absence of gender-neutral HPV vaccination, MSM-targeted strategies would require the implementation of sensitive techniques at an individual level to encourage a large number of MSM to discuss their HPV risk and the availability of HPV vaccine.

\section{Key messages}

- Men who have sex with men (MSM) have poor understanding of the causal role of human papillomavirus (HPV) in the development of anogenital and oral cancers.

- The majority of MSM did not consider themselves at risk of HPV.

- Men who were aware of the virus expressed greater willingness to receive the vaccine.

- The diverse HPV vaccine acceptability measures used in these studies might not indicate actual uptake rates. Future research must use validated tools, able to predict vaccination uptake.

- More research is needed to understand which factors predict HPV vaccine acceptability among MSM with little sexual experience.

\section{Handling editor David A Lewis}

Acknowledgements The authors thank two anonymous reviewers for their useful comments.

Contributors TN and CL designed the review. TN and CJJ extracted the data and contributed to the analyses. All authors contributed to the drafting of the manuscript and approved the final version of the manuscript.

Funding This work was funded through a competitive PhD scholarship from the University of Brighton.

\section{Competing interests None.}

Provenance and peer review Not commissioned; externally peer reviewed.

\section{REFERENCE}

1 Hartwig S, Syrjänen S, Dominiak-Felden G, et al. Estimation of the epidemiological burden of human papillomavirus-related cancers and non-malignant diseases in men in Europe: a review. BMC Cancer 2012;12:30

2 Chaturvedi AK. Beyond Cervical Cancer: Burden of Other HPV-Related Cancers Among Men and Women. J Adolesc Health 2010;46:S20-6.

3 Dunne EF, Nielson CM, Stone KM, et al. Prevalence of HPV Infection among Men: A Systematic Review of the Literature. J Infect Dis 2006;194:1044-57.

4 Machalek DA, Poynten M, Jin F, et al. Anal human papillomavirus infection and associated neoplastic lesions in men who have sex with men: a systematic review and meta-analysis. Lancet Oncol 2012;13:487-500.

5 Palefsky JM, Holly EA, Efirdc JT, et al. Anal intraepithelial neoplasia in the highly active antiretroviral therapy era among HIV-positive men who have sex with men. AIDS 2005:19:1407-14.
6 Nielsen A, Munk C, Kjaer SK. Trends in incidence of anal cancer and high-grade anal intraepithelial neoplasia in Denmark, 1978-2008. Int J Cancer 2012;130:1168-73.

7 Bosch FX, Broker TR, Forman D, et al. Comprehensive control of Human Papillomavirus infections and related diseases. Vaccine 2013:31:11-|31.

8 Ali $\mathrm{H}$, Donovan B, Wand $\mathrm{H}$, et al. Genital warts in young Australians five years into national human papillomavirus vaccination programme: national surveillance data. BMJ 2013:346:f2032

9 Jemal A, Simard EP, Dorell C, et al. Annual Report to the Nation on the Status of Cancer, 1975-2009, Featuring the Burden and Trends in Human Papillomavirus (HPV)-Associated Cancers and HPV Vaccination Coverage Levels. JNCI 2013;105:175-201.

10 European Centre for Disease Prevention and Control. Introduction of HPV vaccines in European Union counties: an update. Stockholm, Luxembourg: European Centre for Disease Prevention and Control; Publications Office [of the European Union] 2012.

11 Wolitski RJ, Stall R, Valdiserri RO. Unequal opportunity: health disparities affecting gay and bisexual men in the United States. New York, USA: Oxford University Press, 2008:1.

12 Palefsky JM, Giuliano AR, Goldstone S, et al. HPV Vaccine against Anal HPV Infection and Anal Intraepithelial Neoplasia. N. Engl J Med 2011;365:1576-85.

13 Poynten IM, Jin F, Templeton DJ, et al. Prevalence, Incidence, and Risk Factors for Human Papillomavirus 16 Seropositivity in Australian Homosexual Men. Sex Transm Dis 2012;39:726-32.

14 Kim JJ. Targeted human papillomavirus vaccination of men who have sex with men in the USA: a cost-effectiveness modelling analysis. Lancet Infect Dis 2010;10:845-52.

15 Lawton MD, Nathan M, Asboe D. HPV vaccination to prevent anal cancer in men who have sex with men. Sex Transm Infect 2013:89:342-3.

16 Petroll $A E$, Mosack KE. Physician awareness of sexual orientation and preventive health recommendations to men who have sex with men. Sex Transm Dis 2011;38:63-7.

17 Moher D, Liberati A, Tetzlaff J. et al. Preferred reporting items for systematic reviews and meta-analyses: the PRISMA statement. Ann Intern Med 2009;151:264-9.

18 Von Elm E, Altman DG, Egger M, et al. The Strengthening the Reporting of Observational Studies in Epidemiology (STROBE) Statement: guidelines for reporting observational studies. Prev Med 2007;45:247-51.

19 Higgins JPT, Altman DG, Gotzsche PC, et al. The Cochrane Collaboration's tool for assessing risk of bias in randomised trials. BMJ 2011;343:d5928.

20 Mehta P, Sharma M. Predictors of HPV vaccine in college men. J Community Med Health Edu 2011;1:111.

21 Bynum S, Brandt $H$, Friedman D, et al. Beliefs, and behaviors: examining human papillomavirus-related gender differences among African American College students. J Am Coll Health 2011;59:296-302.

22 Gerend MA, Barley J. Human papillomavirus vaccine acceptability among young adult men. Sex Transm Dis 2009;36:58-62.

23 Crosby RA, DiClemente RJ, Salazar LF, et al. Gardasil for guys: correlates of intent to be vaccinated. J Mens health 2011;8:119-25.

24 Ferris DG, Waller JL, Miller J, et al. Variables Associated With Human Papillomavirus (HPV) Vaccine Acceptance by Men. J Am Board Fam Med 2009;22:34-42.

25 Tider DS, Parsons JT, Bimbi DS. Knowledge of human papillomavirus and effects on sexual behaviour of gay/bisexual men: a brief report. Int J STD AIDS 2005;16:707-8.

26 Pitts MK, Fox C, Willis J, et al. What do gay men know about human papillomavirus? Australian gay men's knowledge and experience of anal cancer screening and human papillomavirus. Sex Transm Dis 2007;34:170-3.

27 Simatherai $D$, Bradshaw CS, Fairley CK, et al. What men who have sex with men think about the human papillomavirus vaccine. Sex Transm Infect 2008;85:148-9.

28 Reiter PL, Brewer NT, McRee A-L, et al. Acceptability of HPV vaccine among a national sample of gay and bisexual men. Sex Transm Dis 2010;37:197-203.

29 Sundström K, Tran TN, Lundholm C, et al. Acceptability of HPV vaccination among young adults aged 18-30 years-a population based survey in Sweden. Vaccine 2010;28:7492-500

30 Hernandez BY, Wilkens L, Thompson P, et al. Acceptability of prophylactic human papillomavirus vaccination among adult men. Human Vaccin 2010;6:467-75.

31 Thomas EA, Goldstone SE. Should I or shouldn't I: decision making, knowledge and behavioral effects of quadrivalent HPV vaccination in men who have sex with men. Vaccine 2011;29:570-6.

32 Blackwell CW, Eden C. Human papillomavirus and anorectal carcinoma knowledge in men who have sex with men. JANAC 2011:22:444-53.

33 Wheldon CW, Daley EM, Buhi ER, et al. Health beliefs and attitudes associated with HPV vaccine intention among young gay and bisexual men in the southeastern United States. Vaccine 2011:29:8060-5.

34 Pelullo CP, Di Giuseppe G, Angelillo IF. Human Papillomavirus Infection: Knowledge Attitudes, and Behaviors among Lesbian, Gay Men, and Bisexual in Italy. Medeiros R, editor. PLOS ONE 2012;7:e42856

35 Colón-López V, Ortiz AP, Del Toro-Mejías LM, et al. Awareness and knowledge of Human Papillomavirus (HPV) infection among high-risk men of Hispanic origin attending a Sexually Transmitted Infection (STI) clinic. BMC Infect Dis 2012;12:346 
36 Al-Naggar RA. Acceptance and associated factors of HPV vaccination among young male Malaysians. J Community Med Health Educ 2012;1:120.

37 Rank C, Gilbert M, Ogilvie G, et al. Acceptability of human papillomavirus vaccination and sexual experience prior to disclosure to health care providers among men who have sex with men in Vancouver, Canada: implications for targeted vaccination programs. Vaccine 2012;30:5755-60.

38 Sanchez DM, Pathela P, Niccolai LM, et al. Knowledge of human papillomavirus and anal cancer among men who have sex with men attending a New York City sexually transmitted diseases clinic. Int J STD AIDS 2012;23:41-3.

39 Gutierrez $B$, Leung $A$, Jones $K T$, et al. Acceptability of the human papillomavirus vaccine among Urban adolescent males. Am J Mens Health 2012;7:27-36.

40 Lau JTF, Wang Z, Kim JH, et al. Acceptability of HPV vaccines and associations with perceptions related to HPV and HPV vaccines among men who have sex with men in Hong Kong. Gray CM, editor. PLOS ONE 2013;8:e57204.

41 McCusker J, Hill EM, Mayer KH. Awareness and use of hepatitis B vaccine among homosexual male clients of a Boston community health center. Public Health Reports 1990;105:59.
42 Brewer NT, Chapman GB, Gibbons FX, et al. Meta-analysis of the relationship between risk perception and health behavior: the example of vaccination. Health Psychol 2007;26:136-45.

43 Payne JW, Bettman JR, Johnson EJ. Behavioural decision research: a constractive processing perspective. Annu Rev Psychol 1992:43:87-131.

44 Yee J. Understanding correlates of hepatitis B virus vaccination in men who have sex with men: what have we learned? Sexy Transm Infect 2002;78:374-7.

45 Public Health England. Vaccine uptake in men who have sex with men. Hepatitis B3 Survey. Unpublished data. Retrieved on 05/08/2013. http://www.hpa.org.uk/Topics/ InfectiousDiseases/InfectionsAZ/HepatitisB/TheHepB3Survey/

46 Gamagedara N, Weerakoon AP, Zau H, et al. Cross-sectional study of hepatitis B immunity in MSM between 2002 and 2012. Sex Transm Infect 2013;89: A185-6.

47 McRee AL, Reiter PL, Pepper JK, et al. Correlates of comfort with alternative settings for HPV vaccine delivery. Hum Vaccin Immunother 2013;9:42-9.

48 Allen JD, Coronado GD, Williams RS, et al. A systematic review of measures used in studies of human papillomavirus (HPV) vaccine acceptability. Vaccine 2010;28:4027-37. 